\title{
Statistical Analysis of Determinants of Credit Loan Payment in Arba Minch Town, Ethiopia Using Logistic Regression Model
}

\author{
Belayneh Debasu Kelkay*, Zelalem Esubalew \\ Department of Statistics, College of Natural Sciences, Arba Minch University, Arba Minch, Ethiopia \\ Email address: \\ belaynehd@gmail.com (B. D. Kelkay) \\ To cite this article: \\ Belayneh Debasu Kelkay, Zelalem Esubalew. Statistical Analysis of Determinants of Credit Loan Payment in Arba Minch Town, Ethiopia \\ Using Logistic Regression Model. International Journal of Statistical Distributions and Applications. Vol. 3, No. 1, 2017, pp. 7-12. \\ doi: $10.11648 /$ j.ijsd.20170301.12
}

Received: November 15, 2016; Accepted: February 23, 2017; Published: April 26, 2017

\begin{abstract}
Ethiopia has one of the fastest-growing economies in the world and is Africa's second most populous country (IFC, 2012). In developing countries, like Ethiopia, financial resource is important input for continuous development. Most of the peoples living in under poverty line need wide range financial services for consumption, running their business and building assets. Due to lack of collateral, poor people in most cases have no credit access from Banks. Microfinance offers financial service such as loan, savings and micro insurance to the poor people either in individual or in a group basis to those people. The objective of this study isto investigate the factor that affects credit loan payment performance of urban people in ArbaMinchSeachasubcity. For this study the researcher would be used stratified sampling for proportional allocation because this study concerned on strata level.From 15336 total people live in this sub-town a sample of 95 person were randomly selected. The estimation results of the descriptive statistics and the logistic regression model show that age,sex, level of education, family size, attitude,awareness and number of times borrowed are important and significant factors that enhance using of credit loan activity. And the other variable is not significant factors that improve using of credit loan action like, marital status and religious.
\end{abstract}

Keywords: Credit Loan Payment, Logistic Regression, Secha Sub-city

\section{Introduction}

Ethiopia has one of the fastest-growing economies in the world and is Africa's second most populous country (IFC, 2012). Many properties owned by the government during the previous regime have now been privatized and are in the process of privatization. Almost $50 \%$ of Ethiopia's population is under the age of 18 , and even though education enrollment at primary and tertiary level has increased significantly, job creation has not caught up with the increased output from educational institutes. The country must create hundreds of thousands of jobs every year just to keep up with population growth.The economy of Ethiopia is based on agriculture, which accounts for $46.3 \%$ of gross domestic product (GDP), $60 \%$ of exports, and $80 \%$ of total employment.

In Ethiopia, the formal and informal sectors co-exist, with differences in accessibility. Many financial institutions in developing countries provide financial services such as saving and credit to aid several households' enterprises. This is an effort in line with the millennium development goals which seeks to reduce poverty by $50 \%$ by the year 2013 . However, the sustainability and continuity of the financial institution to increase the volume of credit to stimulate the poverty reduction goal depend on the payment rate.

Several microfinance institutions (MFIS) have been established in Ethiopia and have been operating towards resolving the credit access problem of the poor particularly those who engage in little business (Befkadua, 2007). Generally the accessibility of a good financial service is considered as one of the engines of economic development. The establishment and expansion of financial service is also one of the instruments to break the vicious circle of poverty. Government of less developed countries has frequently practiced the policy of providing cheap credit to the agricultural sector through financial intermediaries. This cheap credit, it is hoped, will lower the dependence on the urban money lenders (Pinkie, 1998). 
In developing countries, like Ethiopia, financial resource is important input for continuous development. Most of the peoples living in under poverty line need wide range financial services for consumption, running their business and building assets. Due to lack of collateral, poor people in most cases have no credit access from Banks. Microfinance offers financial service such as loan, savings and micro insurance to the poor people either in individual or in a group basis to those people. The achievement of microfinance activities in Ethiopia is mainly affected by the income of clients, which directly depends on the effectiveness of the small business of borrowers who live in urban areas.

Credit prevention is one of the principal components of urban development, which helps to attain rapid and sustainable growth of urban activities.. This study mainly involved on what are the source and the forms of credit practiced in the area. How the contribution of credit loan payment for the small households. This study is intended to deal with the following research questions:

- What are the factors that determine households likelihood of being credit constrained in Arba Minch town Secha sub city?

- What is the observation of customers regarding service freedom of formal financial institutions in the study area?

- What is the position of different wealth and sex groups' formal and informal credit?

Therefore, the main objective of this study is to investigate the factor that affects credit loan payment performance of peoples in Arba Minch town Sechasub-city by using binary logistic regression.

\section{Methodology}

\subsection{Study Area}

Arba Minch town is located about $454 \mathrm{~km}$ south of Addis Ababa and $275 \mathrm{~km}$ south of Hawassa. Its elevation range from 1200 meter above sea level at the Northern and 1320 above sea level at the southern end. The town has an average temperature $30^{\circ} \mathrm{C}$ and rain fall of $575 \mathrm{~mm}$, and the town has two sub - cities namely Sikela and Secha.

\subsection{Target Population}

The target population for this study would be all people from age 18 and above who live in secha sub-City.

\subsection{Method of Data Collection}

This study uses primary source of data using stratified sampling design method and obtained the data using a welldesigned questionnaire.

\subsection{Sample Size Determination}

The sample sizes depend on level of significance $(\alpha)$, margin of error (d) and estimated of proportion (P\&Q).Therefore, the formula to determine the sample size is: $n_{o}=\frac{z_{\alpha / 2 P q}^{2}}{d^{2}}=\frac{(1.96)^{2}(0.2)(0.8)}{(0.08)^{2}}=96.04=96$, Where $\mathrm{p}=0.2$ and $\mathrm{q}=0.8$ are obtained by conducting pilot survey and $\alpha=0.05$ and $\mathrm{d}=0.08$

Since the value of $\frac{z_{\alpha / 2 P q}^{2}}{d^{2}}$ is greater than $5 \%$, this study uses the value of $n=\frac{n_{o}}{1+\frac{n_{0}}{N}}($ Cochran, third edition, other wise use $\left.\mathrm{n}=n_{o}\right)$.

Thus, $\mathrm{n}=\frac{96}{1+\frac{96}{15336}}=95$

$n_{h=\frac{n}{N}} N_{h}$ Where $n_{h}$ be sample drawn from $h^{t h}$ stratum $N_{h}$ be the population size in the $h^{t h}$ stratum.

$\mathrm{N}=\mathrm{N}_{1}+\mathrm{N}_{2}+\mathrm{N}_{3}$ for three kebele's

Table 1. Stratum of Population Size.

\begin{tabular}{lll}
\hline Stratum & Population & Sample size to be drawn \\
\hline Stratum-1 & $\begin{array}{l}\text { N1=total population of } \\
\text { berekebele }\end{array}$ & $\mathrm{n}_{1}=\frac{N 1 * n}{N}=\frac{3872 * 95}{15336}=24$ \\
Stratum-2 & $\begin{array}{l}\text { N2=total population of } \\
\text { doysakebele }\end{array}$ & $\mathrm{n}_{2}=\frac{N 2 * n}{N}=\frac{9464 * 95}{15336}=59$ \\
Stratum-3 & $\begin{array}{l}\text { N3=total population of } \\
\text { chamokebele }\end{array}$ & $\mathrm{n}_{3}=\frac{N 3 * n}{N}=\frac{2000 * 95}{15336}=12$ \\
\hline
\end{tabular}

\subsection{The Study Variables}

Dependant variable: using of credit loan payment.

Independent variables: sex, age, family size (number of children), educational level, religion, economic status, attitude, number of times borrowed, awareness, marital status.

Table 2. Dependent and Independent variable categories with their coding.

\begin{tabular}{ll}
\hline Variables & Categories \\
\hline Using of credit Loan payment & Yes $=0 \mathrm{No}=1$ \\
Age & $18-30=031-40=141-50+=2$ \\
Sex & Male $=0$ Female $=1$ \\
Religion & Orthodox $=1$ Muslim $=2$ \\
Family size (number of & Protestant $=3$ Catholic=4 Other=5 \\
children) & One child $=0$ Two Child=1Three Child=2 \\
& more than three Child=3 \\
& Elementary $=0$ High School=1 \\
Educational Level & Preparatory $=2$ \\
& Diploma $=3$ Degree $=4$ Master and \\
Economic Status & above $=5$ \\
Attitude & Low $=0 \mathrm{Medium}=1 \mathrm{High}=2$ \\
Awareness & Positive $=0$ Negative $=1$ \\
Number Of Times Borrowed & Yes $=0 \mathrm{No}=1$ \\
\hline
\end{tabular}

2.6. Method of Statistical Data Analysis:Logistic Regression Model

Logistic regression is used when the dependent variable is qualitative in nature or categorical. Qualitative response variable are either binary (dichotomous variable) or multiple category. IN this study binary logistic regression was used.

\subsection{Binary Logistic Regression}

The binary logistic regression model is defined as

$$
\theta(x)=\frac{e^{\beta_{0}+\beta_{1} x_{1}+\beta_{2} x_{2}+\cdots+\beta_{k} x_{k}}}{1+e^{\beta_{0}+\beta_{1} x_{1}+\beta_{2} x_{2}+\cdots+\beta_{k} x_{k}}}
$$


Where $\beta_{0}=$ the constant of the equation

$\beta_{i}=$ the coefficient of the $\mathrm{i}^{\text {th }}$ predictor variable, $\mathrm{i}=1,2, \ldots \mathrm{k}$ $\mathrm{X}_{\mathrm{i}}=\mathrm{i}^{\text {th }}$ explanatory variable of the model.

An alternative form of the logistic regression equation is;

$$
\begin{aligned}
& \operatorname{logit}[\theta(x)]=\log \left[\frac{\theta(x)}{1-\theta(x)}\right] \\
& \quad=\beta_{0}+\beta_{1} x_{1}+\beta_{2} x_{2}+\cdots+\beta_{k} x_{k}
\end{aligned}
$$

\subsection{Odds Ratio}

The odds ratio is the ratio between two odds. The odds of some event happening is defined as the ratio of the probability of occurrence to the probability of non occurrence. That is, the odd of the event $\mathrm{E}$ is given by: odds $(E)=\frac{\operatorname{pr}(E)}{\operatorname{pr}(\text { not } E)}=\frac{\operatorname{pr}(E)}{1-\operatorname{pr}(E)}$

The odds ratio (OR) for two events $\mathrm{A}$ and $\mathrm{B}$ given by:

$$
O R=\frac{\operatorname{odds}(A)}{\operatorname{odds}(B)}
$$

\subsection{Parameter Estimation for Logistic Regression}

To estimate the parameters of logistic regression model, the

\section{Result and Discussion}

\begin{tabular}{|c|c|c|c|}
\hline Variable & Categories & Frequency & Percent \\
\hline \multirow{3}{*}{ Age } & $18-30$ & 40 & 42.1 \\
\hline & $31-40$ & 40 & 42.1 \\
\hline & $41-50+$ & 15 & 15.8 \\
\hline \multirow{3}{*}{ Sex } & male & 74 & 77.9 \\
\hline & female & 21 & 22.1 \\
\hline & orthodox & 58 & 61.1 \\
\hline \multirow{3}{*}{ Religion } & protestant & 33 & 34.7 \\
\hline & catholic & 3 & 2.1 \\
\hline & other & 1 & 1.1 \\
\hline \multirow{6}{*}{ Educational level } & elementary & 17 & 17.9 \\
\hline & high school & 40 & 42.1 \\
\hline & preparatory & 13 & 13.7 \\
\hline & diploma & 11 & 11.6 \\
\hline & degree & 13 & 13.7 \\
\hline & master and above & 1 & 1.1 \\
\hline \multirow{4}{*}{ Marital status } & single & 30 & 31.6 \\
\hline & divorced & 3 & 3.2 \\
\hline & Widowed & 2 & 1.1 \\
\hline & married & 60 & 63.2 \\
\hline \multirow{5}{*}{ Family size } & no child & 33 & 34.7 \\
\hline & one child & 21 & 22.1 \\
\hline & two child & 18 & 18.9 \\
\hline & three child & 12 & 12.6 \\
\hline & more than three child & 11 & 11.6 \\
\hline \multirow{2}{*}{ Economic status } & low & 56 & 58.9 \\
\hline & medium & 39 & 41.1 \\
\hline \multirow{2}{*}{ Attitude } & no & 69 & 72.6 \\
\hline & Yes & 26 & 27.4 \\
\hline \multirow{2}{*}{ Awareness } & No & 69 & 72.6 \\
\hline & Yes & 26 & 27.4 \\
\hline \multirow{3}{*}{ Number of borrowed } & once & 7 & 7.4 \\
\hline & twice & 11 & 11.6 \\
\hline & More than twice & 12 & 12.6 \\
\hline
\end{tabular}

\subsection{Descriptive Statistics}

Table 3. Frequency distribution of categorical variables. and non-iterative weighted least squares method. When the assumption of normality of the predictors does not hold, the non- iterative weighted least squares method is less efficient. In contrast, the maximum likelihood estimation method is appropriate for estimating the logistic model parameters due to this less restrictive nature of the underlying assumptions.

$$
\begin{gathered}
\text { Consider the logistic regression model } \\
P\left(x_{i}\right)=\frac{e^{X_{i}^{\prime} \beta}}{1+e^{X_{i}^{\prime} \beta}} . \\
L(\beta / y)=\prod_{i=1}^{n} P\left(y_{i} \mid X_{i}^{\prime}\right) \\
=\prod_{i=1}^{n}\left[\frac{e^{X_{i}^{\prime} \beta}}{1+e^{X_{i}^{\prime} \beta}}\right]^{y_{i}}\left[\frac{1}{1+e^{X_{i}^{\prime} \beta}}\right]^{\left(1-y_{i}\right)}
\end{gathered}
$$

The objective of ML estimation is to get an estimator $\hat{\beta}=\left(\hat{\beta}_{0}, \hat{\beta}_{1}, \hat{\beta}_{2}, \ldots, \hat{\beta}_{k}\right)$ of $\beta$ which maximizes the likelihood function. two estimation methods mostly used are maximum likelihood 


\subsection{Inferential Statistics}

Table 4. Summary of personal chi-square test.

\begin{tabular}{|c|c|c|c|c|c|c|}
\hline \multirow{2}{*}{ Variable } & \multirow{2}{*}{ Category } & \multicolumn{2}{|c|}{ Using of credit payment } & \multirow[b]{2}{*}{ df } & \multirow{2}{*}{ Chi-square } & \multirow[b]{2}{*}{ Sig. } \\
\hline & & No(\%) & Yes (\%) & & & \\
\hline \multirow{3}{*}{ Age } & $18-30$ & $22(55.0 \%)$ & $18(45.0 \%)$ & & & \\
\hline & $31-40$ & $33(82.5 \%)$ & $7(17.5 \%)$ & 2 & 11.125 & 0.004 \\
\hline & $41-50+$ & $6(40.0 \%)$ & $9(60.0 \%)$ & & & \\
\hline \multirow{3}{*}{ Sex } & male & $46(62.2 \%)$ & $28(37.8 \%)$ & & & 0434 \\
\hline & female & $15(71.4 \%)$ & $6(28.6 \%)$ & 1 & 0.611 & 0.434 \\
\hline & orthodox & $39(67.2 \%)$ & $19(32.8 \%)$ & & & \\
\hline \multirow{3}{*}{ Religion } & protestant & $20(60.6 \%)$ & $13(39.4 \%)$ & 4 & 2946 & 0567 \\
\hline & catholic & $1(50.0 \%)$ & $1(50.0 \%)$ & 4 & 2.940 & T \\
\hline & other & $1(100 \%)$ & $0(0.0 \%)$ & & & \\
\hline \multirow{6}{*}{ Educational level } & elementary & $5(29.4 \%)$ & $12(70.6 \%)$ & & & \\
\hline & high school & $22(55.0 \%)$ & $18(45.0 \%)$ & & & \\
\hline & preparatory & $12(92.3 \%)$ & $1(7.7 \%)$ & 5 & 21025 & 0001 \\
\hline & diploma & $10(90.9 \%)$ & $1(9.1 \%)$ & 5 & 21.225 & 0.001 \\
\hline & degree & $11(84.6 \%)$ & $2(15.4 \%)$ & & & \\
\hline & master and above & $1(100 \%)$ & $0(0.0 \%)$ & & & \\
\hline \multirow{4}{*}{ Marital status } & single & $21(70.0 \%)$ & $9(30.0 \%)$ & & & \\
\hline & divorced & $2(66.7 \%))$ & $1(33.3 \%)$ & 4 & 2.9466 & 0.564 \\
\hline & widowed & $0(0.0 \%)$ & $1(100 \%)$ & 4 & 2.9400 & 0.004 \\
\hline & married & $37(61.7 \%)$ & $23(38.3 \%)$ & & & \\
\hline \multirow{5}{*}{ Family size } & no child & $21(63.6 \%)$ & $12(36.4 \%)$ & & & \\
\hline & one child & $13(61.9 \%)$ & $8(38.1 \%)$ & & & \\
\hline & two child & $12(66.7 \%)$ & $6(33.3 \%)$ & 4 & 1.156 & 0.049 \\
\hline & three child & $9(75.0 \%)$ & $3(25.0 \%)$ & & & \\
\hline & more than three child & $6(54.5 \%)$ & $5(45.5 \%)$ & & & \\
\hline \multirow{2}{*}{ Economic status } & low & $31(55.4 \%)$ & $25(44.6 \%)$ & 1 & 4653 & 0.31 \\
\hline & medium & $30(76.9 \%)$ & $9(23.1 \%)$ & 1 & 4.030 & 0.01 \\
\hline \multirow{2}{*}{ Attitude } & no & $55(79.7 \%)$ & $14(20.3 \%)$ & 1 & 26.356 & 0.000 \\
\hline & yes & $6(23.1 \%)$ & $20(76.9 \%)$ & 1 & 20.550 & 0.000 \\
\hline \multirow{3}{*}{ Awareness } & no & $55(79.7 \%)$ & $14(20.3 \%)$ & & 26.356 & 0.000 \\
\hline & yes & $6(23.1 \%)$ & $20(76.9 \%)$ & 1 & 26.556 & 0.000 \\
\hline & once & $3(42.9 \%)$ & $4(57.1 \%)$ & & & \\
\hline \multirow{3}{*}{$\begin{array}{l}\text { Number of } \\
\text { borrowed }\end{array}$} & twice & $1(9.1 \%)$ & $10(90.9 \%)$ & 3 & 34028 & 0000 \\
\hline & more than twice & $3(25.0 \%)$ & $9(75.0 \%)$ & 3 & 34.020 & .000 \\
\hline & no borrowed & $54(83.1 \%)$ & $11(16.9 \%)$ & & & \\
\hline
\end{tabular}

The hypothesis to be tested under this condition is:

$\mathrm{H}_{\mathrm{o}}$ : there are no association between using credit loan payment and explanatory variables.

$\mathrm{H}_{1}$ : Not $\mathrm{H}_{\mathrm{o}}$

Level of significance $\alpha=0.05$.

Decision rule: If $\mathrm{X}_{\text {cal }}^{2}>\mathrm{X}^{2}{ }_{0.05}(1)$, it's reject Ho or null hypothesis and P-value $<\alpha=0.05$,it's fail to reject Ho.

For age of respondents, from the above chi-square test table 4, P-value is less than $\alpha$-level of significance (i.e. Pvalue $0.004<\alpha=0.05)$ at $\mathrm{df}=2$ and Chi-square $=11.125$, it's reject the null hypothesis; we can be concluded that there is association (dependent) between age ofrespondents and using of credit loan.

For sex: since p- value is greater than $\alpha$ - level of significance (i.e. p-value $0.434>\alpha=0.05$ ) at Chi-square 0.611 with $\mathrm{df}=1$, then it's fail to reject the null hypothesis at $5 \%$ level of significance thus it can be concluded that sex and using of credit loan is no association (independent) between sex of respondent and using of credit loan.

For religion of the respondent: from the Chi-square test above table, since the P-value is greater than common level of significance (i.e P-value $=0.567>\alpha=0.05$ ) at value of Chi-square $=2.946$ with $\mathrm{df}=4$, it is fail to reject $\mathrm{H}_{0}$, we can be concluded that there isno association between religion of the respondent and using of credit loan.

For educational level of the respondent, since $\mathrm{p}$ - value is less than common level of significance (i.e $p$-value $=0.001<0.05$ ) at value of Chi-square $=21.225$ with $\mathrm{df}=5$, then it's reject the null hypothesis at $5 \%$ level of significance thus it can conclude that the religion of the respondent and utilization of credit loan are dependent or there is association between the religious of the respondent and using of credit loan.

For economic level of the respondent from the above table Chi-square test of hypothesis, $\mathrm{P}$-value is greater thancommon level of significance (i.e. P-value $0.31>\propto=0.05$ ) itChi-square $=$ 4.653 with $\mathrm{df}=1$, it is fail toreject the null hypothesis, We can conclude that there is noassociation (independent) between economic level of the respondent and using of credit loan.

\subsection{Binary Logistic Regression Analysis}

Table 5. Omnibus Tests of Model Coefficients.

\begin{tabular}{lllll}
\hline & & Chi-square & df & Sig. \\
\hline Step 1 & Step & 83.728 & 25 & .000 \\
& Block & 83.728 & 25 & .000 \\
& Model & 83.728 & 25 & .000 \\
\hline
\end{tabular}


Omnibus Tests of Model Coefficients gives us a ChiSquare of 83.728 which is significant at $5 \%$ level. This is a test of the null hypothesis that adding the predictors to the model has not significantly increased our ability to predict utilization of credit loan. Since our omnibus test is significant we can conclude that adding the predictors to the model has significantly increased our ability to predict utilization of credit loan.

\subsection{Model Summary}

Table 6. Cox and Snell Statistic.

\begin{tabular}{llll}
\hline \multirow{2}{*}{ Step } & $\begin{array}{l}\mathbf{- 2} \text { Log } \\
\text { likelihood }\end{array}$ & $\begin{array}{l}\text { Cox \& Snell R } \\
\text { Square }\end{array}$ & $\begin{array}{l}\text { Nagelkerke R } \\
\text { Square }\end{array}$ \\
\hline 1 & $40.050($ a) & .586 & .805 \\
\hline
\end{tabular}

Cox and Snell or Nagelkerke $\mathrm{R}^{2}$ is an analogous statistic in logistic regression to the coefficient of determination $\mathrm{R}^{2}$ in linear regression, but not a close analog. The model summary provides some approximations of $\mathrm{R}^{2}$ statistician logistic
regression.Cox and Snell's $\mathrm{R}^{2}$ attempts to imitate multiple $\mathrm{R}^{2}$ based on 'likelihood'. In this study Cox and snellR ${ }^{2}$ indicate that $58.6 \%$ of the variation in the dependent variable using credit loan is explained by explanatory variables.

\subsection{Hosmer and Lemeshow Test}

Table 7. Hosmer-Lemeshow test

\begin{tabular}{llll}
\hline Step & Chi-square & df & Sig. \\
\hline 1 & 2.843 & 8 & .944 \\
\hline
\end{tabular}

Hosmer-Lemeshow test is used to assess the overall goodness of fit of the fitted model. The P-value is 0.944 for the Hosmer-Lemeshow goodness of fit test is greater than 0.05 , we will not reject the null hypothesis that there is no difference between observed and model predicted values, implying that the model estimates are adequate to fit the data at an acceptable level.

Table 8. Variable in the equation for binary logistic regression.

\begin{tabular}{|c|c|c|c|c|c|c|c|}
\hline & & B & S.E. & Wald & df & Sig. & $\operatorname{Exp}(B)$ \\
\hline & Age & & & 9.158 & 2 & 0.010 & \\
\hline & Age(1) & -5.551 & 2.157 & 6.622 & 1 & 0.010 & 0.004 \\
\hline & Age(2) & -6.900 & 2.287 & 9.102 & 1 & 0.003 & 0.001 \\
\hline & $\operatorname{Sex}(1)$ & 3.508 & 1.449 & 5.858 & 1 & 0.016 & 33.380 \\
\hline & Religion & & & 2.895 & 4 & 0.576 & \\
\hline & Religion(1) & -12.459 & 40.992 & 0.000 & 1 & 1.000 & 0.000 \\
\hline & Religion(2) & -10.787 & 412.92 & 0.000 & 1 & 1.000 & 0.000 \\
\hline & Religion(4) & -32.067 & 541.459 & 0.000 & 1 & 1.000 & 0.000 \\
\hline & Education level & & & 11.598 & 5 & 0.041 & \\
\hline & Educationlevel(1) & 24.354 & 192.54 & 0.000 & 1 & 1.000 & 377.260 \\
\hline & Educationlevel(2) & 21.421 & 12.94 & 4.670 & 1 & 0.039 & 201.463 \\
\hline Step & Educationlevel(3) & 13.899 & 401.95 & 0.000 & 1 & 1.000 & 1087.527 \\
\hline \multirow[t]{17}{*}{ 1(a) } & Educationlevel(4) & 18.068 & 492.95 & 0.000 & 1 & 1.000 & 702.811 \\
\hline & Educationlevel(5) & 19.650 & 402.954 & 0.000 & 1 & 1.000 & 3542.973 \\
\hline & Maritalstatus(2) & 11.000 & 40192.885 & 0.000 & 1 & 1.000 & 5985.188 \\
\hline & Maritalstatus(3) & 25.441 & 56841.383 & 0.000 & 1 & 1.000 & 111.306 \\
\hline & Maritalstatus(4) & 6.503 & 40192.885 & 0.000 & 1 & 1.000 & 667.461 \\
\hline & Familysize & & & 8.204 & 4 & 0.024 & \\
\hline & Familysize(1) & 8.835 & 3.424 & 6.657 & 1 & 0.010 & 6871.124 \\
\hline & Familysize(2) & 3.938 & 2.223 & 3.138 & 1 & 0.076 & 51.317 \\
\hline & Familysize(3) & .374 & 1.990 & 0.035 & 1 & 0.851 & 1.454 \\
\hline & Familysize(4) & -1.528 & 2.406 & 0.403 & 1 & 0.525 & 0.217 \\
\hline & Economicstatus $(1)$ & 0.757 & 1.489 & 0.259 & 1 & 0.611 & 2.132 \\
\hline & Attitude(1) & -0.106 & 5.632 & 8.534 & 1 & 0.046 & 0.899 \\
\hline & Numberofborrowed & & & 6.430 & 3 & 0.092 & \\
\hline & Numberofborrowed(1) & 1.344 & 5.581 & 0.058 & 1 & 0.810 & 3.833 \\
\hline & Numberofborrowed(2) & 9.222 & 6.352 & 2.107 & 1 & 0.147 & 1013.365 \\
\hline & Numberofborrowed(3) & 3.663 & 5.794 & 0.400 & 1 & 0.527 & 38.994 \\
\hline & Constant & -17.360 & 69616.172 & 0.000 & 1 & 1.000 & 0.000 \\
\hline
\end{tabular}

Therefore from the above table the $\mathrm{p}$-values of respective variables are less than 0.05 for age of respondents for 31-40 and 41-50+, sex of female respondents, educational level of respondents for high school, family size of the respondents have one child, and attitude of therespondents are significantly association with the response variable. Thus, there is enough evidence to conclude that there is a significant relationship or association at $5 \%$ level of significance between predictor variables like age, sex, educational level, family size and attitude of the respondents with credit loan at $5 \%$ level of significance.

The fitted logistic regressionmodel is: Logit (pi) $=\log$ $(\mathrm{pi} / 1-\mathrm{pi})=\beta_{0}+\beta_{1} x_{1}+\beta_{2} x_{2}+\cdots+\beta_{k} x_{k}$. So the logit model is used to predict the explanatory variable of the model.

Logit (pi) $=-17.360-5.551 \mathrm{x}_{1}+3.508 \mathrm{x}_{2}+24.354 \mathrm{x}_{3}+$ $8.835 \mathrm{x}_{4}-0.106 \mathrm{x}_{5}$ 
Where $\mathrm{x}_{1}=$ age of the respondent

$\mathrm{X}_{2}=$ sex of respondent is female

$\mathrm{X}_{3}=$ educational level is high school

$\mathrm{X}_{4}=$ family of one child

$\mathrm{X}_{5}=$ attitude of the respondents

\subsection{Interpretation Using Odds Ratio}

The odds ratio is equal to 1 when no association exists. It is the odd of success given a certain condition exists divided by the odds of failure given that same condition does not exist. One advantage of the logit function is that it provides an estimate of the odds ratio for each predictor in the model.

- Theestimated odds ratio for age group between 18-30 and $41-50+$ is 0.4 and 0.1 respectively as compared with the age group 18-30. This means that using of credit loan on the age interval $31-40$ and $41-50+$ are greater effect on using credit loan about 0.4 and 0.1 times that of age 18-30 (reference group).

- The estimated odds ratio for sex (1) or female of the respondents is $38.0 \%$ as compared with male this means females are higher effect on using credit loan than male.

\section{Conclusion and Recommendation}

This study considers the factors that affect using of credit loan payment in Arba Minch town Secha sub-city in 2007 E.C. stratified random sampling is used for data collection and analysed bay logistic regression model. From the empirical result credit loan is significantly related with age, sex, education level, family size, awareness, attitude and number of borrow times on the other hand using of credit loan is not significant relation with religion economic status and marital status. Based on the findings of the study the following are recommended

- Governments should expand the awareness about the utilization of credit loan payment for people who live in secha sub-town and also expands the access of insurance company service in their village to minimize the transportation cost and waiting time.

- Governments should give sufficient knowledge about using credit loan in order to people knows the advantage of credit loan and most of the people have the owner of using credit loan.

- Government should give reward for more times borrower in order to facilitate them and people to participate using of credit loan to see those reward people.
- If the urban people get credit on time they can utilize the loan effectively and get a better output. Therefore, timely credit service help people to use the loan in appropriate way and perceived importance of loan by the borrowers and accelerates the chance of the repayment of the loan at proper time.

\section{References}

[1] Aryeetey, Ernest, and William Steel, (1995).Saving s collectors and financial intermediation in Ghana. Savings and Development 19(2):189-199.

[2] AnbeseTenaye, (2003).Pattern of credit use and its impact on small farmer's income.A study in Dire Dwa area. Eastern Ethiopia.un published M.Sc.

[3] Beck man, T.N. and Foster.R.S.(1969). Credit and collection, Management.

[4] Befkadu, (2007). Outreach and financial performance of analysis of micro finance institution in Ethiopia. African Economic Conference.

[5] Belay Kebede, (1998). Credit and factor impeding loan payment performance of small holder in central high lands of Ethiopia.

[6] Hussein Hamada, (2007). Farm House holds Economic Behavioral in Imperfect Financial Markets, Doctoral thesis, Swedish University of Agricultural Sciences, Uppsala.

[7] IFC (2012)"Private Sector Boosts Ethiopia's Growth".

[8] KebedeKoomsa, (1995).Agricultural credit Analysis. National Agricultural policy work shop.

[9] Pinkie, (1998). Formal and Informal sector interaction in rural credit markets. Journal of development economics 56:265280 .

[10] Sherraden, M. (2001).Asset building policy and programs for the poor.InT.Shapiro and E. Wolff (Eds.), Asset for the poor.

[11] Solomon Damte,(1996) "credit to poor Households, The case of financing micro enterprises in the DebreBerhan town, North shoa, in the Ethiopian Economy: poverty and poverty alleviation" proceeding of the $5^{\text {th }}$ annual, conference on the Ethiopian economy, Addis Ababa.

[12] TeferiZewdu,(2000) micro finance and the poor: The case of dedebit credit and saving Institution (DESCI).

[13] Vigno, Lawara. (1993). Credit scoring model for development Banks: An African case study, saving and Development vol. XVII. 